relay work, have stated that the only telephone relay which actually operated as a result of an enormous expenditure of money, time, etc., was the telephone relay that worked on the occasion referred to. I felt that, in view of the President's statement, it should be mentioned that there was at least one telephone relay that had actually worked.

Mr. CARTY:-I wish to have the privilege of moving a vote of thanks for the very interesting papers read by Mr. Abbott and $\mathrm{Mr}$. Dommerque, calling attention to the fact that in the question of telephone rates there is an engineering side.

Mr. Аввотт:-I would suggest, Mr. President, that the motion should include Mr. Carty, for I think he has contributed as much, and perhaps more than the others, to the pleasure of the evening.

President Steinmetz:-The Chair takes pleasure in putting the motion, with the amendment suggested.

The motion was carried, and the meeting on motion adjourned.

\title{
Discussion at Chicago, March 28th, 1902.
}

\section{Mr. R. H. Pierce in the Chair.}

Mr. F. J. Dommerque:-It is certainly astonishing what a progressive movement the telephone has made in the last few years. During the first eighteen or twenty years of the régime of the Bell telephone company, the expansion of the telephone business was very limited. For instance, in Chicago in 1899 there were not more than 22,000 subscribers. At present the number is double that. The same is true of most cities all over the country, except where there is an independent plant. Why should this movement of increase in numbers of telephones have taken place just in the last few years? Personally I can see no other reason than that the Bell company, during the period when no competitor was in the field, knew that it was cheaper and netted them more revenue, if they had a limited number of subscribers and charged a high rate, than to charge a low rate and have a large number of subscribers, for with a large number of subscribers there is a good deal more labor and expense which has to be paid for. With the appearance of the independent company in the field, the Bell company, it seems to me, has had to change its policy by reducing the rates and obtaining more subscribers. A great deal is due to the independent movement for such a large increase in the number of subscribers, I am sure. It may be that Mr. Hibbard does not feel the way I do, but I thought it was well at least to call attention to this fact.

With reference to Mr. Abbott's paper. I would like to call attention to a few points: On the third page, after the introduction, the author states: "It is possible to-day for anyone to build a first-class telephone exchange, and with good care, shrewd and expert management, to give service that cannot be excelled, at the lowest possible price. Such, I say, is possible, but, un- 
fortunately, it is rarely done. On the contrary, a very erroneous idea prevails in the mind of most of the independent companies as to the requirements and limitations of telephony," etc.

According to this statement, I judge that he means that all they do, in the independent work, is to put up a stick, tie a line to it, and the work is all done and they have a telephone.

I want to call attention to Table II., General Telephone Statistics. At the bottom of that page Mr. Abbott says: "This table is compiled from various sources, and is believed to be fairly accurate within about six months." Furthermore, he says that " B " and "I " signify "Bell " and "Independent " plants respectively. The first city mentioned is Baltimore, where the Bell people have 6,300 telephones and the independent company 6,000 . You will observe they are pretty close together in the number of telephones, and I think the independent company did well to get that many where the Bell company had been operating twenty years.

The next city mentioned where the two companies are operating is Cleveland, where the Bell company has 13,744 subscribers and the independent company has 9,000. Again the independent company has a pretty good showing.

This table shows that in Columbus the Bell company only is operating, but as a matter of fact, there is an independent company there also, which has a good many subscribers. The same is true of Indianapolis. There is also an independent company in Pittsburgh with a great many subscribers; also in St. Louis and Minneapolis. Coming back to where the comparison is given between the Bell and independent companies in Cleveland, the Bell company is recorded as having 13,744 subscribers against 9,000 for the independent company. That means $50 \%$ more. When you look at the next columns you will notice that the Bell company uses 83,484 wire miles to connect $50 \%$ more subscribers than the independen ${ }^{+}$has. The independent company uses 27,000 wire miles, and therefore the Bell company needs three times as many wire miles to connect $50 \%$ more subscribers than the independent. You will notice that the Bell company needs 3.2 wire miles to connect, per subscriber, while the independent people need only 1.4 .

We will make another comparison. In Rochester, the Bell company has 4,200 telephones in use and the independent company has an equal number. The number of wire miles per subscriber for the Bell company is 3; independent, 1.25. This is not quite three times as much. The independent companies give continuous service in Cleveland and in Rochester at lower rates than the Bell licensees, which is justified, as the independent engineers build their plants more economically than do the Bell engineers, as proved above.

Then again the author says: "Half-a-dozen of the prominent citizens of some town conceive the idea of a telephone exchange, an ordinance is rushed through the City Council, of which one or 
more of the 'prominent citizens' are members, a company is formed; enough stock subscription is raised to pay current office expenses and the labor of erecting a few miles of wire." etc., etc. $\mathrm{He}$ continues and at the end says: "Indeed, the preliminary puff is already felt, as is testified by the present lamentable financial condition in Cleveland, for if ever the true epitaph is written over the unfortunate Everett-Moore syndicate it will read, "Died of too much telephone." Why cannot the syndicate see its way clear to part with the telephone holdings, for which there are plenty of bidders? Because the telephone properties are good dividend payers. It was the street railways that caused all the trouble.

On page 382 the author says, "The independent companies are weak in their lack of coherence, feeble in possessing but few exchanges in the larger towns, and almost none in the great cities, and powerless in the toll and long-distance field." Of course, the statement that the independent companies are powerless in the toll and long-distance field is very true, and when the independent people have the toll and long-distance connections, which they will have, then the competition with the Bell company will be very close. I have found that in all the cities where the independent people have started exchanges, the money invested in these exchanges has been put up mostly by the prominent citizens and the best merchants and bankers in those cities. In St. Louis a great deal of the money was invested by the prominent brewers. They are the largest shareholders of the independent company there, and it stands to reason that those men will look out that the money which they have invested in their own city is taken care of. The principal shares of the Bell telephone company in all the prominent cities in the United States are owned by the Boston interests. It is a very hard thing to fight against the local company, if the prominent local people are interested in the independent movement.

As far as investment is concerned, of course at the beginning of the independent movement there was a good deal of speculation, as Mr. Abbott states in his paper very correctly, and to a great extent there is speculation still, but it is only an exception at the present day if the independent movement is not worked upon a proper and sound financial basis. The independent engineers have made many mistakes, but they have shown that they know enough to construct a plant for less money than the Bell company, and the plants give good service; if they did not give good service, the subscribers would not patronize them

There is a table on page 384 which gives the probable installation cost per station of a telephone plant sufficient to serve $15 \%$ of the population. Just preceding this table there is this statement: "It is possible, even in such a city as New York, to install a telephone plant at a cost not to exceed $\$ 60$ per substation." That price seems very low. The price of substation apparatus is given as $\$ 15$. Now, a telephone for common battery service 
ought not to cost more than $\$ 9$ or $\$ 10$, and installation $\$ 2$, making $\$ 12$. The cost of wire plants (subscribers' and trunk lines) is $\$ 21$ a subscriber. I cannot very well believe that this is possible in a large city like New York. Furthermore, the author says that the cost of switchboard apparatus for subscribers' and trunk lines is $\$ 12.11$ and $\$ 6$ respectively. If we were not to get more than this, we switchboard manufacturers would go out of business, so I think the total charge of $\$ 54$ is very low, and I think the independent company would not undertake the work at that price in New York; I believe that Mr. Abbott's figures are high enough for small cities.

The Chairman:-I notice that Mr. Abbott, in his paper, suggests that the method of charge be based on the number of messages and also on the length of time the subscriber is talking. He suggests the use of a meter, which he says would cost about $\$ 3$, to record the number of connections and also the total time that the subscriber talks. I suppose he means during the month. I must say that I cannot see how this will give a fair record; that is, how the record would be an indiration of the expense to the company of furnishing such service, even if there was a meter which could be installed for this purpose for that price. It would seem to me, offhand, that such a meter would very likely record more where poor service was furnished than where good service was furnished. I would like to hear an expression of opinion as to that from some one who is in the telephone business.

Mr. Dommerque:-As far as the cost of the meter is concerned, I think one may be produced for $\$ 3$, but it seems to me that the whole principle of measuring service in the same way that it is measured in electric lighting, is wrong. In fact a comparison between telephone and electric light service is not the right one.

Those of you who have been in Europe and have traveled on the street cars on the Continent, know the difficulty of the street car system, where you pay according to the distance you are going. If you are going one mile you receive a red ticket; two miles a green ticket, etc. If you are going " through" you receive another ticket. In addition you have to save your ticket, as now and then an inspector will enter the car and will ask to see your ticket. This makes traveling very troublesome. The Continental companies are now introducing systems like those which we have here, and the people like the change, as it makes their traveling much less bothersome. On the elevated railroads here, you pay your nickel and are carried as far as you wish to go, whether one block or a dozen. You never complain if you are charged a nickel for riding one block, the same fare as one pays who rides a dozen blocks. The same thing, it seems to me, should hold true in connection with the telephone business. We want to do a great volume of business and the subscriber should be unobstructed and unlimited as to the number and duration of calls he makes. The idea of the use of a meter at the subscriber's station is not correct anyway, as such a meter 
would record every call made, regardless of whether the subscriber obtained the desired party or not, $i$. e., all busy calls would be recorded and consequently paid for, if the meters were at the subscriber's station. Therefore, it is necessary that the meter should be at the exchange, so that it may be acted upon by the apparatus controlled by the calling subscriber as well as by the apparatus controlled by the subscriber called for. Anyone familiar with the use of such meters can tell a story about them.

\section{Abstract of Discussion at Minneapolis, Minn., April 7TH, 1902.}

The Minnesota members of the American Institute of ElecTRICAL ENGINEERS and other gentlemen interested, held a meeting in the Electrical Building at the University of Minnesota on April 7th to discuss the three Institute papers on Telephony. The discussion was participated in by nearly all of the nineteen present.

Among other points, attention was called to the fact that capacity effects were of much greater relative importance in telephony than in electric lighting or power transmission, electromagnetic induction having very little importance along the line. While the dominant fundamental tones of an ordinary man's voice range around " lower C," having about 132 vibrations per second, and therefore give a frequency comparable with those commonly used for electric lighting and power transmission, the overtones, which give character to the voice, have several times that frequency. Since the current or the quantity of electricity absorbed in electrostatically charging the parallel wires of a telephone or other transmission line is proportional to the frequency, it follows that the components of the current waves due to the high-frequency overtones are dissipated along the line much more rapidly than the lower frequency fundamental tones. This effect changes the character of the sound so that the average voice as heard over the telephone is quite different from that heard in immediate converse. This is one reason why it is frequently difficult to recognize a familiar voice over the line and why those who know each other only by communicating through the telephone, find quite different voices when they meet face to face. The blurring of sounds in long-distance telephony is due partly to the fact that certain sounds such as "s " and "e " are of very much higher pitch than others, such as "o " and " $u$," consequently they are obscured in many cases. When the consonants are inferred from the vowel sounds rather than from being heard, the obscuring of some vowels and the emphasizing of others makes it surprising that intelligent conversation can be carried on as far as is common. The apparent contradiction that the telephone girls with voices pitched higher can maintain communication intelligently over lines which give simply a con- 